\title{
Inadvertent Percutaneous Endoscopic Gastrostomy Tube Placement through the Transverse Colon to the Stomach Causing Intractable Diarrhea: A Case Report
}

\author{
David T. Burke, ${ }^{1}$ Andrew I. Geller, ${ }^{1}$ Alexios G. Carayannopoulos, ${ }^{2}$ and Richard Goldstein ${ }^{3}$ \\ ${ }^{1}$ Department of Physical Medicine and Rehabilitation, Emory University School of Medicine, Atlanta, GA 30322, USA \\ ${ }^{2}$ Department of Neurosurgery, Spine Center, Lahey Clinic, Burlington, MA 01805, USA \\ ${ }^{3}$ Spaulding Rehabilitation Hospital, Harvard Medical School, Boston, MA 02115, USA
}

Correspondence should be addressed to David T. Burke, dburke2@emory.edu

Received 10 January 2011; Revised 24 August 2011; Accepted 8 September 2011

Academic Editor: Wahid Wassef

Copyright ( 2011 David T. Burke et al. This is an open access article distributed under the Creative Commons Attribution License, which permits unrestricted use, distribution, and reproduction in any medium, provided the original work is properly cited.

\begin{abstract}
Background. Among patients with chronic disease, percutaneous endoscopic gastrostomy (PEG) tubes are a common mechanism to deliver enteral feedings to patients unable to feed by mouth. While several cases in the literature describe difficulties with and complications of the initial placement of the PEG, few studies have documented the effects of a delayed diagnosis of a misplaced tube. Methods. This case study reviews the hospitalization of an 82 year old male with an inadvertent placement of a PEG tube through the transverse colon. Photos of the placement in the stomach as well as those of the follow up colonoscopy, and a recording of the episodes of diarrhea during the hospitalization were made. Results. The records of this patient reveal complaints of gastrointestinal distress and diarrhea immediately after placement of the tube. Placement in the stomach was verified by endoscopy, with discovery of the tube only after a follow up colonoscopy. The tube remained in place after this discovery, and was removed weeks after the diarrhea was unsuccessfully treated with antibiotics. After tube removal, the patient recovered well and was sent home.
\end{abstract}

\section{Background}

Many patients with chronic disease lack the ability to maintain adequate nutrition by mouth [1]. Percutaneous endoscopic gastrostomy (PEG) tubes are a well-established, effective, and a relatively safe means to deliver enteral feedings to patients unable to feed by mouth [2-4]. In acute rehabilitation hospitals, it is common for a nasogastric (NG) tube to be replaced by a PEG tube to allow for enteral feeding over a long period of time. While surgical gastrostomies have been relatively common, the use of PEG now seems to be the preferred method for those in need of such gastrointestinal access [5-9].

There are a number of cases in the literature describing difficulties with and complications of initial placement of PEG tubes, as well as those that develop thereafter [10-19]. For the most part, these complications are realized at the time of initial placement and immediate remedial action is taken. The importance of initial placement has also been shown to be a significant factor in preventing gastric ulcers [5]. Later complications of PEG tube placement include infection at placement site, leaks of the tube or at the insertion site, gastrointestinal (GI) bleeding, and peritonitis $[6,7,20,21]$. An unusual but very dangerous complication described in the literature is that of the "buried bumper" syndrome $[8-10,22]$. This syndrome, which can present early or late, involves the migration of the internal bumper of the PEG tube through or into the abdominal wall resulting in gastrointestinal bleeding, stomach perforation, peritonitis, and, in some cases, even death [11]. In addition to these complications, there have been cases of PEG tube malpositioning through the liver [23-28], duodenum [12], jejunum [29-31], gastric arteries [32], and transverse colon [33-36], with varying ill effects. This case study documents the course of a patient whose PEG tube placement into the stomach was found to involve the inadvertent penetration of the transverse colon with resultant intractable diarrhea. To our knowledge, this represents the first documented 
case of transverse colonic insertion in the setting of direct visualization by endoscopy.

\section{Case/Hospital Course}

This is a case of an 82-year-old male who suffered multiple traumatic injuries including subdural hematoma after being struck by a motor vehicle while walking on the street. He required intubation and mechanical ventilation for respiratory distress, and was weaned off the ventilator after about one week. The patient was advanced to oral (PO) feedings, but complained of right upper quadrant tenderness. An abdominal ultrasound revealed a normal biliary tree with sludge in the gall bladder. A CT of the abdomen revealed an ileus, and an NG tube was placed. Total parenteral nutrition (TPN) was subsequently initiated for nutritional support. With demonstrated ability to swallow, the patient's NG tube was removed and he was advanced to a dental soft diet. His oral intake was poor at that time, but thought to be improving. With no further surgical or intensive care unit intervention under consideration, the patient was transferred to the medical team at the brain injury unit of the acute rehabilitation hospital.

During his first week at in the brain injury unit, the patient continued to poorly demonstrate PO intake. A nasogastric tube was ordered. The patient was extremely intolerant of the NG, and placement was unsuccessful. A PEG tube was ordered and placed by the gastroenterology team under upper endoscopic visualization. The endoscope was passed under direct visualization. During this procedure the patient had been placed in the supine position and the stomach was insufflated to oppose the gastric and abdominal wall. The abdominal wall was marked and the trocar needle was introduced through the abdominal wall under direct endoscopic view. A snare was introduced through the endoscope and opened in the gastric lumen. The guide wire was passed through the trocar and into the open snare. The snare was closed around the guide wire. A $20 \mathrm{Fr}$ microinvasive gastrostomy tube was tied to the guide wire and pulled through the mouth and into the stomach. The trocar needle was removed and the gastrostomy tube was pulled out from the stomach. The external bumper was attached to the tube and the gastrostomy tube was cut to remove the guidewire. The placement was noted to be uncomplicated. No abnormalities were noted in the gastric wall or the esophagus at the time of placement.

During the next week, however, the patient began to develop diarrhea. Dietary modifications did not improve the diarrhea, which proceeded to worsen. The patient's stool tested positive for Clostridium difficile. He was started on a course of metronidazole, but showed no improvement. (See Figure 1). The infectious disease team was consulted, and recommendations were made to extend the treatment. Multiple courses of metronidazole were administered over several weeks.

During this time period, the patient underwent both ultrasonographic imaging and laboratory testing to investigate his gastrointestinal distress. These studies revealed a distended gallbladder with sludging and a mildly elevated

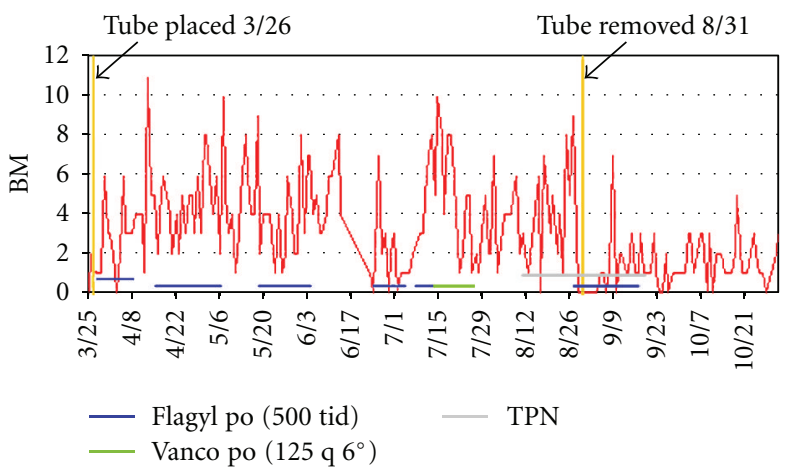

FIGURE 1: Bowel movement frequency per day for the patient's entire length of stay at a rehabilitation hospital.

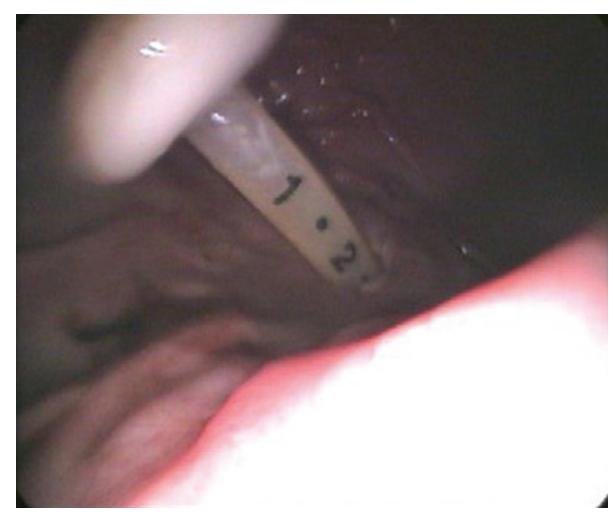

FIgure 2: Photograph demonstrating PEG tube termination inside the lumen of the stomach.

lipase, respectively, but were otherwise unremarkable. A KUB was performed, which failed to show obstipation. An upper endoscopy was also ordered, and revealed that the G-tube was still in place without evidence of erosion or gastric irritation. An abdominal CT was ordered using IV and oral contrast. These were read as revealing mild perianal inflammatory changes containing air and distal rectal wall thickening with no drainable fluid, and no CT evidence of inflammatory colitis. It was noted that a G-tube was seen in situ. A repeat CT was ordered 6 weeks later, again noting a gastric tube in place with additional comments of no bowel obstruction and perianal collections containing air and fluid. With the development of symptoms including occasional nausea and vomiting, the patient was sent for a head CT, which was unremarkable for new findings.

The patient had hemoccult-positive stools that were thought to be secondary to hemorrhoids. In spite of this, a colonoscopy was ordered, showing nodular mucosa in the rectum, which was thought to be nonspecific and nondiagnostic for colitis. At that procedure it was discovered that the PEG tube had pierced the transverse colon, entering and exiting it terminating in the stomach (see Figures 2, 3, and 4). No other GI abnormalities were noted. GI surgery was consulted and recommended that the PEG be maintained, as it was thought to be an unlikely source of diarrhea and of no acute concern. The patient continued to have 
TABLE 1: Two-sample $t$-test with unequal variances.

\begin{tabular}{lccccc}
\hline & Days & Mean stools/day & Std. error & Std. deviation & (95\% conf. interval) \\
\hline With G-tube & 146 & 3.835616 & .2031931 & 2.455191 & 1.434014 \\
Without G-tube & 61 & 1.47541 & .1662945 & 1.298801 & 1.142771 \\
Combined & 207 & 3.140097 & .1687944 & 2.428529 & 2.807311 \\
\hline
\end{tabular}

Satterthwaite's degrees of freedom $=193.982$.

$P<0.0005$.

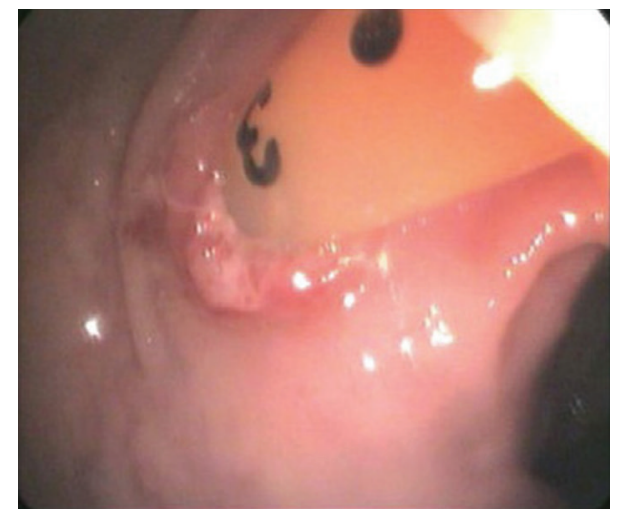

FIgure 3: Photograph demonstrating the PEG tube exiting from the wall of the transverse colon.

C. difficile-positive loose stools. As the diarrhea persisted through four full courses of metronidazole, the infectious disease consultants agreed to switch to $\mathrm{PO}$ vancomycin and cholestyramine. These failed to produce improvement in the diarrhea.

Tube feeds were intermittently held while TPN was initiated to rest the bowel. There was interval improvement in the number of stools per day with off-tube feeds, and subsequent resumption of diarrhea once the feeds were restarted. The tube feeds were again held until the patient was reevaluated by GI surgery. With a failure to respond to multiple courses of metronidazole and a course of vancomycin, the patient was sent for a repeat colonoscopy.

This second colonoscopy revealed the PEG tube had migrated, apparently dislodging from the stomach and coming to rest in the transverse colon. Left unanswered was when this migration had occurred, though a CT two weeks earlier had demonstrated proper placement, with the tube terminating in the stomach. At that colonoscopy, the tube was surgically removed and a new tube was placed without complication. The frequency of the diarrhea immediately declined and the patient's symptoms improved (see Figure 1). A review of the data demonstrated the mean number of diarrheal episodes per day to be 3.8 during the entire period with the "tube in" and 1.5 per day with the "tube out," for a difference of about 2.4 episodes/day (see Table 1). For a statistical comparison, we calculated a $t$ test assuming-conservatively - that the variances were not equal $(P<0.00005)$. We also did a Wilcoxon rank sum test (see Table 2), as a nonparametric alternative to the $t$-test. Again, the $P$ value was found to be statistically significant

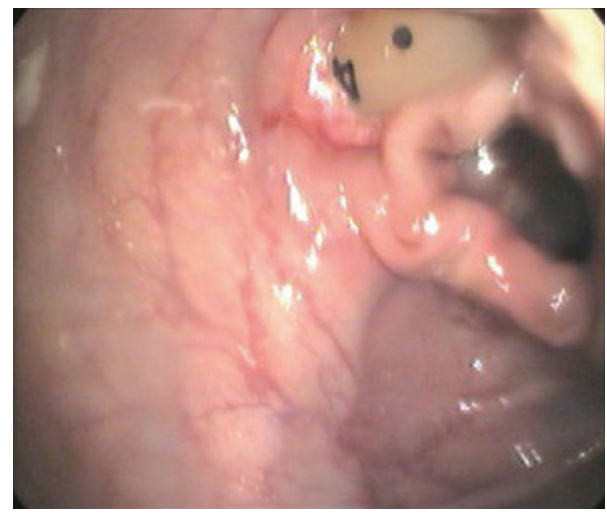

FIGURE 4: Photograph demonstrating PEG tube entering the wall of the transverse colon.

TABLE 2: Two-sample Wilcoxon rank-sum (Mann-Whitney) test.

\begin{tabular}{lccc}
\hline & Days & Rank sum & Expected \\
\hline With G-tube & 146 & 17861 & 15184 \\
Without G-tube & 61 & 3667 & 6344 \\
Combined & 207 & 21528 & 21528 \\
\hline
\end{tabular}

$P<0.00005$.

$(P<0.00005)$. Moreover, the output from this procedure also gives an interesting result shown in the last line of the output: the proportion of pairs where the episode for the "tube in" period is greater than the episodes for the "tube out" period. Pairing each "tube in" day with each "tube out" day yields 8,906 pairs of days. In $80 \%$ of these pairs, there are found to be more episodes of diarrhea for the "tube in" days than for the "tube out" days.

The patient's PEG tube feedings were resumed and the patient did reasonably well. Thereafter, he began to demonstrate improved PO intake and was able to participate in more therapy without diarrhea or excessive weakness. His PEG tube was removed after he maintained adequate oral nutrition. The patient was discharged shortly thereafter to a skilled nursing facility. At the time of followup 6 months later, the patient was living at home with his wife, without any recurrence of previous gastrointestinal complaints.

\section{Discussion}

This case describes a PEG inadvertently placed through the transverse colon and into the stomach, despite intraprocedural direct visualization with an endoscope. Previous cases of 
malpositioning and colonic migration have been reported, though without the use of intra-procedural endoscopy [7, $8,15,30,33-35,37-45]$. A comparison of the patient's bowel patterns before and after the removal seems to demonstrate that placement of the tube caused an increase in bowel motility and frequency. Although a concurrent bowel infection has been shown to complicate the development of diarrhea or alter its manifestations [46], the data presented in this paper provide reasonable evidence that the PEG tube placement clearly contributed to the diarrhea.

This case seems valuable to the practicing physician for two reasons. First, it demonstrates that even under direct intra-procedural visualization, a PEG tube may pierce other viscera. This suggests that other complications of enteral access [47] may likewise result, despite the employment of putatively excellent preventative measures. This is sobering given the current governmental pressure to defund the treatment of potentially foreseeable complications [48-50]. Second, this study does demonstrate that irritation caused by the piercing of the transverse colon may increase bowel motility and be a cause of recalcitrant diarrhea. To our knowledge, this is the first demonstration of this association. In cases of intractable diarrhea misplacement of the PEG must therefore be added to the physician's differential.

\section{References}

[1] M. H. DeLegge, "Enteral access in home care," Journal of Parenteral and Enteral Nutrition, vol. 30, no. 1, pp. S13-S20, 2006.

[2] J. J. Mamel, "Percutaneous endoscopic gastrostomy," The American Journal of Gastroenterology, vol. 84, no. 7, pp. 703710, 1989.

[3] W. L. Gauderer, J. L. Ponsky, and R. J. Izant, "Gastrostomy without laparotomy: a percutaneous endoscopic technique," Journal of Pediatric Surgery, vol. 15, no. 6, pp. 872-875, 1980.

[4] R. M. Preshaw, "A percutaneous method for inserting a feeding gastrostomy tube.," Surgery Gynecology and Obstetrics, vol. 152, no. 5, pp. 658-660, 1981.

[5] J. Kanie, H. Akatsu, Y. Suzuki, H. Shimokata, and A. Iguchi, "Mechanism of the development of gastric ulcer after percutaneous endoscopic gastrostomy," Endoscopy, vol. 34, no. 6, pp. 480-482, 2002.

[6] K. M. Dwyer, D. D. Watts, J. S. Thurber, R. S. Benoit, and S. M. Fakhry, "Percutaneous endoscopic gastrostomy: the preferred method of elective feeding tube placement in trauma patients," The Journal of Trauma, vol. 52, no. 1, pp. 26-32, 2002.

[7] M. S. Platt and D. C. Roe, "Complications following insertion and replacement of percutaneous endoscopic gastrostomy (PEG) tubes," Journal of Forensic Sciences, vol. 45, no. 4, pp. 833-835, 2000.

[8] R. W. Shallman, R. G. NorFleet, and J. M. Hardache, "Percutaneous endoscopic gastrostomy feeding tube migration and impaction in the abdominal wall," Gastrointestinal Endoscopy, vol. 34, no. 4, pp. 367-368, 1988.

[9] S. Klein, B. R. Heare, and R. D. Soloway, "The "buried bumper syndrome": a complication of percutaneous endoscopic gastrostomy," The American Journal of Gastroenterology, vol. 85, no. 4, pp. 448-451, 1990.

[10] P. Goodman, M. S. Levine, and H. P. Parkman, "Extrusion of PEG tube from the stomach with fistula formation: an unusual complication of percutaneous endoscopic gastrostomy," Gastrointestinal Radiology, vol. 16, no. 4, pp. 286-288, 1991.

[11] G. K. Anagnostopoulos, P. Kostopoulos, and D. M. Arvanitidis, "Buried bumper syndrome with a fatal outcome, presenting early as gastrointestinal bleeding after percutaneous endoscopic gastrostomy placement," Journal of Postgraduate Medicine, vol. 49, no. 4, pp. 325-327, 2003.

[12] D. M. Panicek, D. K. Ewing, R. H. Gottlieb, and F. S. Chew, "Gastrostomy tube pancreatitis," Pediatric Radiology, vol. 18, no. 5, pp. 416-417, 1988.

[13] Y. J. Joo, J. H. Koo, and S. H. Song, "Gastrocolic fistula as a cause of persistent diarrhea in a patient with a gastrostomy tube," Archives of Physical Medicine and Rehabilitation, vol. 91, no. 11, pp. 1790-1792, 2010.

[14] G. S. Lohiya, L. Tan-Figueroa, and V. Krishna, "Intermittent diarrhea as a delayed presentation of percutaneous endoscopic gastrostomy (PEG)-associated fistula," Journal of the American Board of Family Medicine, vol. 23, no. 5, pp. 681-684, 2010.

[15] D. Okutani, K. Kotani, and S. Makihara, "A case of gastrocolocutaneous fistula as a complication of percutaneous endoscopic gastrostomy," Acta Medica Okayama, vol. 62, no. 2, article no. 9, pp. 135-138, 2008.

[16] K. Tong and Z. Khan, "Unexplained diarrhea in a patient with a percutaneous endoscopic gastrostomy (PEG) tube," Endoscopy, vol. 39, supplement 1, p. E69, 2007.

[17] E. B. Gottsfried, A. B. Plumser, and M. R. Clair, "Pneumoperitoneum following percutaneous endoscopic gastrostomy. A prospective study," Gastrointestinal Endoscopy, vol. 32, no. 6, pp. 397-399, 1986.

[18] M. O. Senac Jr. and F. A. Lee, "Small-bowel volvulus as a complication of gastrostomy," Radiology, vol. 149, no. 1, p. 136, 1983.

[19] E. Ong, U. Bohmler, and D. Wurbs, "Splenic injury as a complication of endoscopy: two case reports and a literature review," Endoscopy, vol. 23, no. 5, pp. 302-304, 1991.

[20] M. R. Taheri, H. Singh, and D. R. Duerksen, "Peritonitis after gastrostomy tube replacement: a case series and review of literature," Journal of Parenteral and Enteral Nutrition, vol. 35, no. 1, pp. 56-60, 2011.

[21] S. P. Schrag, R. Sharma, N. P. Jaik et al., "Complications related to percutaneous endoscopic gastrostomy (PEG) tubes. A comprehensive clinical review," Journal of Gastrointestinal and Liver Diseases, vol. 16, no. 4, pp. 407-418, 2007.

[22] Z. Fireman, N. Yunis, D. Coscas, D. Zamir, Y. Wagner, and A. Sternberg, "The buried gastrostomy bumper syndrome," Harefuah, vol. 131, no. 3-4, pp. 92-143, 1996.

[23] R. A. Chaer, D. Rekkas, J. Trevino, R. Brown, and N. J. Espat, "Intrahepatic placement of a PEG tube," Gastrointestinal Endoscopy, vol. 57, no. 5, pp. 763-765, 2003.

[24] C. Gubler, S. M. Wildi, and P. Bauerfeind, "Liver injury during PEG tube placement: report of two cases," Gastrointestinal Endoscopy, vol. 61, no. 2, pp. 346-348, 2005.

[25] T. F. Wiggins, R. Kaplan, and M. H. DeLegge, "Acute hemorrhage following transhepatic PEG tube placement," Digestive Diseases and Sciences, vol. 52, no. 1, pp. 167-169, 2007.

[26] R. Guloglu, K. Taviloglu, and O. Alimoglu, "Colon injury following percutaneous endoscopic gastrostomy tube insertion," Journal of Laparoendoscopic and Advanced Surgical Techniques Part A, vol. 13, no. 1, pp. 69-72, 2003.

[27] Y. Kinoshita, H. Udagawa, Y. Kajiyama et al., "Cologastric fistula and colonic perforation as a complication of percutaneous endoscopic gastrostomy," Surgical Laparoscopy and Endoscopy, vol. 9, no. 3, pp. 220-222, 1999. 
[28] D. M. Saltzberg, K. Anand, P. Juvan, and I. Joffe, "Colocutaneous fistula: an unusual complication of percutaneous endoscopic gastrostomy," Journal of Parenteral and Enteral Nutrition, vol. 11, no. 1, pp. 86-87, 1987.

[29] I. Siddique, M. Krishnamurthy, S. Choubey, P. Gudavalli, T. Bharathan, and B. R. Pachter, "Colocutaneous fistula: a rare and silent complication of percutaneous endoscopic gastrostomy," Digestive Diseases and Sciences, vol. 41, no. 2, pp. 301304, 1996.

[30] S. E. Smith and T. V. Clancy, "Colocutaneous fistula. A rare complication of percutaneous gastrostomy," North Carolina Medical Journal, vol. 59, no. 2, pp. 80-82, 1998.

[31] A. S. Karhadkar, H. J. Schwartz, and S. K. Dutta, "Jejunocutaneous fistula manifesting as chronic diarrhea after PEG tube replacement," Journal of Clinical Gastroenterology, vol. 40, no. 6, pp. 560-561, 2006.

[32] C. A. M. Schurink, H. Tuynman, P. Scholten et al., "Percutaneous endoscopic gastrostomy: complications and suggestions to avoid them," European Journal of Gastroenterology and Hepatology, vol. 13, no. 7, pp. 819-823, 2001.

[33] T. Yamazaki, Y. Sakai, K. Hatakeyama, and Y. Hoshiyama, "Colocutaneous fistula after percutaneous endoscopic gastrostomy in a remnant stomach," Surgical Endoscopy, vol. 13, no. 3, pp. 280-282, 1999.

[34] H. S. Kim, D. K. Lee, S. K. Baik, and S. O. Kwon, "Endoscopic management of colocutaneous fistula after percutaneous endoscopic gastrostomy," Endoscopy, vol. 34, no. 5, p. 430, 2002.

[35] E. T. Fernandes, R. Hollabaugh, S. D. Hixon, and G. Whitington, "Late presentation of gastrocolic fistula after percutaneous gastrostomy," Gastrointestinal Endoscopy, vol. 34, no. 4, pp. 368-369, 1988.

[36] P. Y. Marcy, N. Magné, J. Lacroix, and C. Bailet, "Late presentation of a gastrocolic fistula after percutaneous fluoroscopic gastrostomy," Journal Belge de Radiologie, vol. 87, no. 1, pp. 17-20, 2004.

[37] W. Amann, H. J. Mischinger, A. Berger et al., "Percutaneous endoscopic gastrostomy (PEG): 8 years of clinical experience in 232 patients," Surgical Endoscopy, vol. 11, no. 7, pp. 741744, 1997.

[38] A. van Gossum, B. DesMarez, and M. Cremer, "A colo-cutaneous-gastric fistula: a silent and unusual complication of percutaneous endoscopic gastrostomy," Endoscopy, vol. 20, no. 4, p. 161, 1988.

[39] M. M. Stefan, G. W. Holcomb, and A. J. Ross, "Cologastric fistula as a complication of percutaneous endoscopic gastrostomy," Journal of Parenteral and Enteral Nutrition, vol. 13, no. 5, pp. 554-556, 1989.

[40] H. C. Roozrokh, A. Ripepi, and K. Stahlfeld, "Gastrocolocutaneous Fistula as a complication of peg tube placement," Surgical Endoscopy, vol. 16, no. 3, pp. 538-539, 2002.

[41] V. Pitsinis and P. Roberts, "Gastrocolic fistula as a complication of percutaneous endoscopic gastrostomy," European Journal of Clinical Nutrition, vol. 57, no. 7, pp. 876-878, 2003.

[42] Y. Chen, Y. H. Ni, and H. S. Lai, "Gastrocolocutaneous fistula in a child with congenital short bowel syndrome: a rare complication of percutaneous endoscopic gastrostomy," Journal of the Formosan Medical Association, vol. 103, no. 4, pp. 306-310, 2004.

[43] W. N. Baskin, "Acute complications associated with bedside placement of feeding tubes," Nutrition in Clinical Practice, vol. 21, no. 1, pp. 40-55, 2006.
[44] S. A. Berger and E. J. Zarling, "Colocutaneous fistula following migration of PEG tube," Gastrointestinal Endoscopy, vol. 37, no. 1, pp. 86-88, 1991.

[45] C. Kilmartin, G. L. Brotzman, and P. Regan, "Colocutaneous fistula as a complication of PEG tube placement," Journal of Family Practice, vol. 43, no. 1, pp. 76-78, 1996.

[46] S. Adachi, "Study on the diarrhea in patients with perctaneous endoscopic gastrostomy - influence of Clostridium difficile on the diarrhea," Japanese Journal of Gastroenterology, vol. 102, no. 4, pp. 484-485, 2005.

[47] S. A. McClave and W. K. Chang, "Complications of enteral access," Gastrointestinal Endoscopy, vol. 58, no. 5, pp. 739-751, 2003.

[48] A. Milstein, "Ending extra payment for "never events"stronger incentives for patients' safety," The New England Journal of Medicine, vol. 360, no. 23, pp. 2388-2390, 2009.

[49] N. M. Bilimoria, "CMS "never events" and other new trends in quality health care standards for hospitals," Health Care Law Monthly, vol. 2008, no. 12, pp. 2-10, 2008.

[50] A. S. Mattie and B. L. Webster, "Centers for medicare and medicaid services' "never events": an analysis and recommendations to hospitals," Health Care Manager, vol. 27, no. 4, pp. 338-349, 2008. 


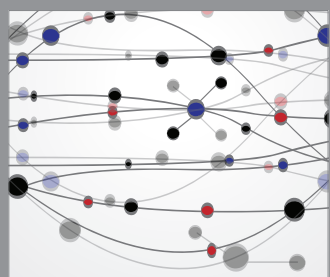

The Scientific World Journal
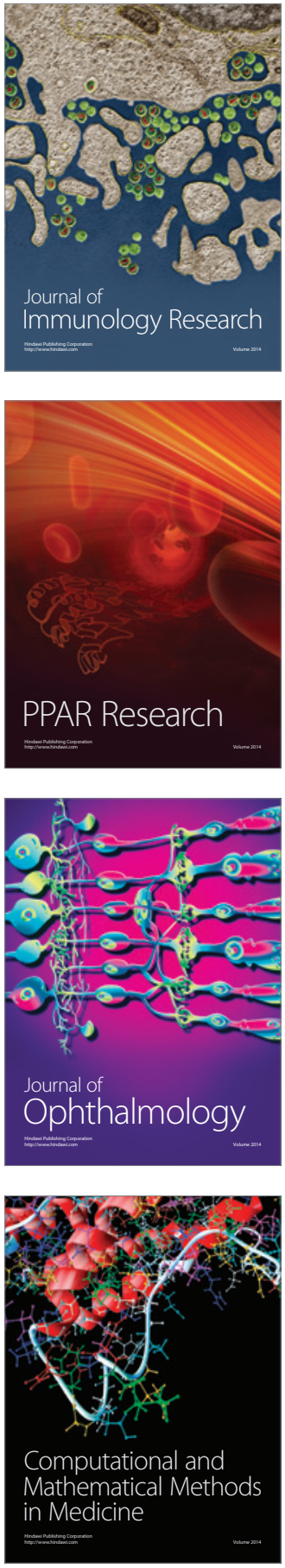

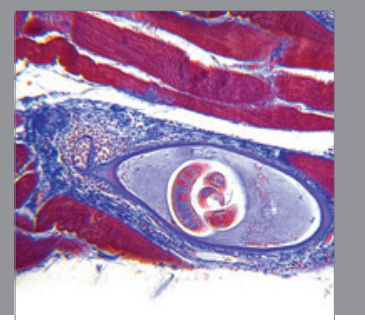

Gastroenterology

Research and Practice
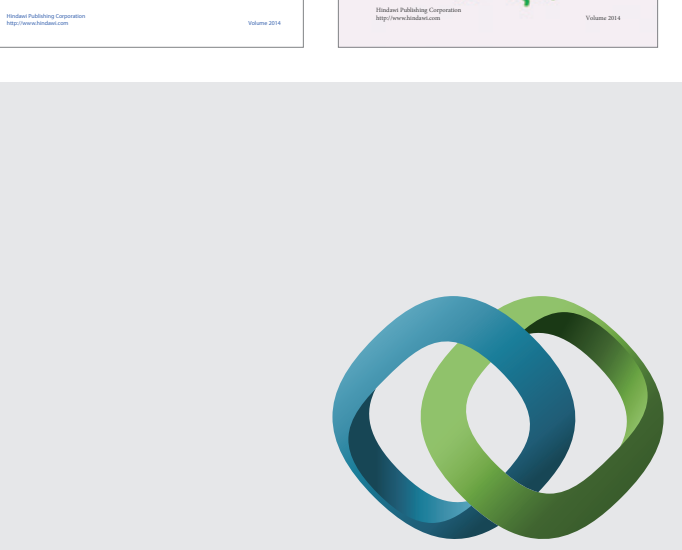

\section{Hindawi}

Submit your manuscripts at

http://www.hindawi.com
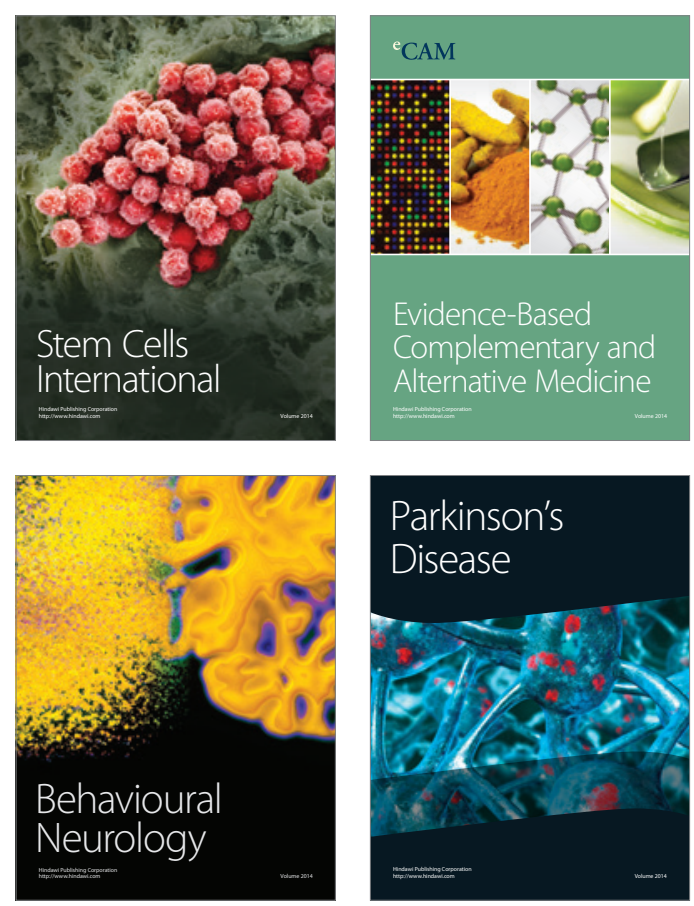

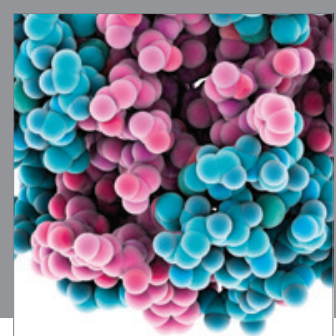

Journal of
Diabetes Research

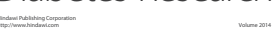

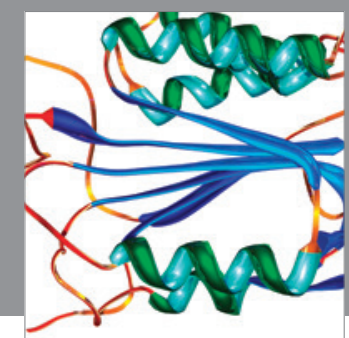

Disease Markers
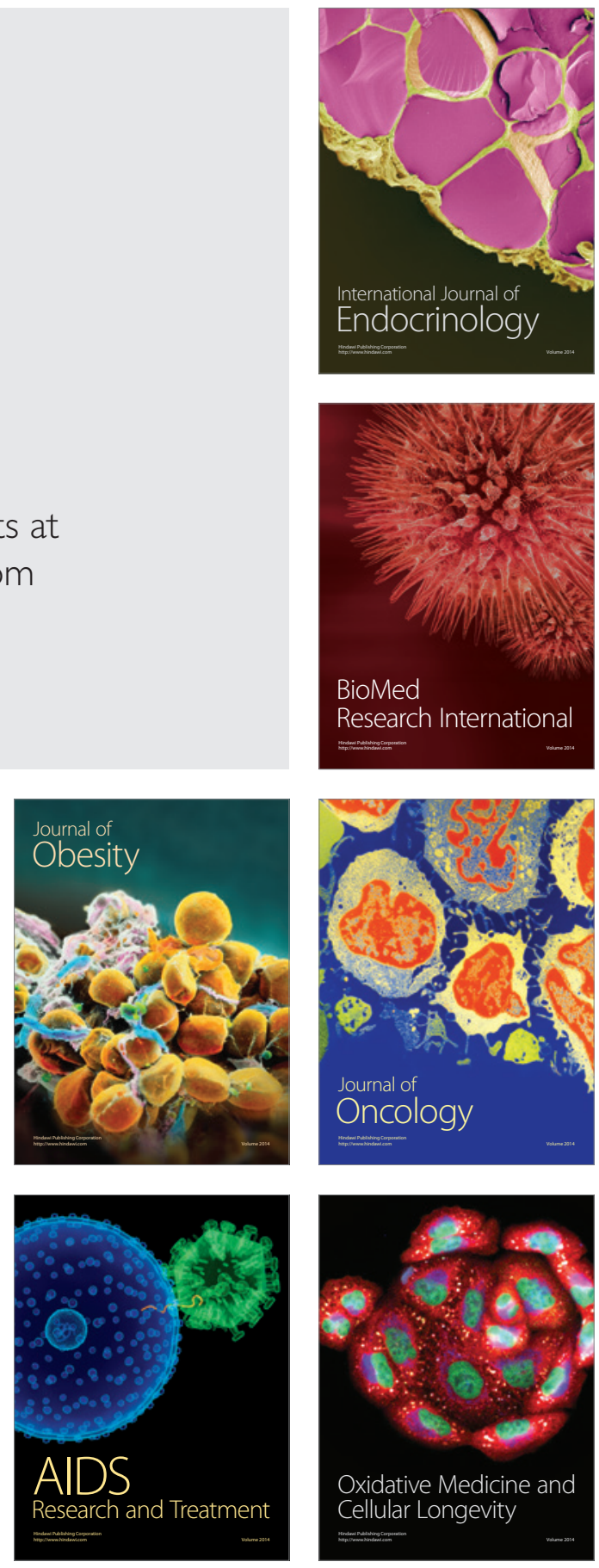